\title{
EMPLOYEE ENGAGEMENT IN AN IT COMPANY
}

\author{
Maja Džepina', \\ Lazar Dražeta ${ }^{1}$, \\ Borivoje Đokić2
}

\author{
${ }^{1}$ Singidunum University, \\ Belgrade, Serbia \\ ${ }^{2}$ Keiser University, \\ Fort Lauderdale, Florida, USA
}

Correspondence:

Maja Džepina

e-mail:

maja.dzepina@gmail.com

\begin{abstract}
:
Job satisfaction is an attitudinal variable that reflects feelings of employees about their job. It is directly linked to the level of employee engagement and work performance, thus representing one of the key elements of organizational culture. In this paper we used a job facets approach that focuses on different aspects of job(s) to enable a more complete picture of job satisfaction. Engagement survey was devised around nine different categories (facets) that represent critical job aspects. Each facet was defined by 2-10 questions that are scaled using 5 optional grades to answer. The survey was carried out in an organization within the short period of time and has achieved a very high response rate. The results have shown significant differences both between various job facets as well as certain factors (expressed by survey questions) within the same category. Furthermore, the activities that may help improve the specific aspects of employee engagement are discussed.
\end{abstract}

Key words:

employee engagement, job satisfaction, organizational culture, survey, IT.

\section{INTRODUCTION.}

Organisational culture affects all aspects of organisational life, including the way in which people interact with each other, perform their work and dress. It is closely linked to numerous facets of an organisation, including job satisfaction. The need to examine the concept of job satisfaction from the scientific point of view has emerged as a result of growing interest and desire to improve business policies and the overall decision-making process within an organisation, as numerous research has shown that the level of employee engagement positively correlates with employee satisfaction. Namely, greater employee engagement leads to better employee performances and business results, which is one of the principal goals of any organisation (Spector, 2008).

Research pointing to significance of employee engagement has led to it being measured in a great number of organisations. Any organisation that aims to be successful needs to establish this type of communication with its employees, primarily as it would bring multiple benefits to it. This type of research is of vital importance in the companies such as the one used in our study, i.e., the companies whose employees are highly valued experts, and where business decisions may have a considerable bearing on employee retention and turnover. 
In such context, it can be defined as service-profit chain, which is actually an indicator of relationship between profitability, customer loyalty and satisfaction, employee loyalty and productivity. The relationships in the chain indicate the following: Profit and growth are mainly stimulated by customer/ employee loyalty; Loyalty is a direct result of their satisfaction; Satisfaction is largely influenced by the value of services provided to customers/ users; Value is created by satisfied, loyal and highly productive employees; Employee satisfaction results primarily from high-quality support services and policies that enable employees to deliver results to customers (Harvard Business Review, 2014.).

The aforementioned shows that the concepts of organizational culture and job satisfaction depend on the quality of relationships and business decisions, which an issue that is further explored within the human resources and organizational behavior sector. Accordingly, the authors shall provide the theoretical background on these two research fields.

\section{HUMAN RESOURCES AND ORGANISATIONAL BEHAVIOR}

Fierce competition in the market, which is becoming global in some sectors such as IT, has made it difficult to define practices that can lead to enhanced competitive advantage. In modern times characterised by perpetual changes and innovations, a good idea and a man as its initiator, are the safest way towards achieving competitive advantage and knocking the socks off the rival companies. Accordingly, human resource management has been constantly developing with the aim to achieve desirable results and development at both individual and organisational level. The principal goals of management at an individual level inlcide performance and quality, employee satisfaction and their long-term loyalty to an organisation. Depending on the organisational level, the goals are concerned with an increase of the average productivity, improvement in working conditions and market survival (Petković, Janićijević i Bogićević, 2010).

Research aimed at identifying the links between human resource management practices and perfromance, i.e. finding practices that would lead to perfromance gain. Richard and Thomson (1999) claim that there is a positive correlation between innovative and sophisticated practices of human resource management and greater business performance. Also, numerous researchers highlight that policies and practices should be perceived in groups, i.e. a particular set of interrelated practices that will have a greater impact on business outcomes, than when implementing a single practice or several of them (Torrington, Hayll, Taylor 2004).

Seven key policies for managing human capital have been proposed: employment security, selective hiring of new emplyees; self-managed teams and decentralisation of decision-making as the basic principles of organisational design; higher compensation contigent on organisational performance; extensive training; reduced status distinctions and barriers; extensive sharing of financial and performance information throughout the organisation and growth and development of an organisation with additional profit (Torrington, Hayll, Taylor 2004).

Our research is primarily based on examining personal attitudes and evaluation of employees as individuals. Therefore, it is necessary to provide the theoretical background of organizational behavior. The same as human resource management, organizational behavior examines individual behavior and group behavior within an organisation. They only differ in terms of the topics they cover. Namely, organisational behavior covers topics such as personality, emotions and affection, motivation, social concept and identity, decision making, justice and trust, leadership, groups and teams, organizational culture and climate. On the other hand, human resources primarily deal with the analysis of employee engagement, selection, training and development, performance assessment, quality of business life, strategic human resource management.

Organisational behavior is a field of study that examines the impact of individuals, groups and structures on behavior within an organization, with the aim to achive growth of an organization and greater efficiency. That implies that organizational behavior can be analysed at three levels: individual, group and organisational (Robbins and Judge, 2013).

The relationship between organizational behavior and human resources is based on the fact that human resource management can be used as a means to shape organizational behavior. The effective use of human resources enables creating employee perceptions and behavior, in compliance with the interests and goals of an organization.

As a matter of fact, the factors of organizational behavior at an individual level need to be included in any human resource practice, and they form attitudes on the issues considered relevant for successful functioning of an organization as a whole (an example of such relationship is the impact of formal and informal communication in modern entreprises). 
In order to specify the fields that can be affected, it is necessary to list the factors that influence behavior in an organization, such as: personal characteristics of employees and individual differences, attitudes, types of personality, contributions, orientations and roles in an organization; Job satisfaction and motivation to perform job assignments; the level of employee engagement; loyalty to an organization; functionality of an organization; organizational culture (Armstrong, 2006).

In accordance with our research, we shall provide a theoretical review of some of those factors, namely organizational culture and job satisfaction. Special segment shall be devoted to employee engagement, as the principal subject of this research.

\section{ORGANISATIONAL CULTURE AND JOB SATISFACTION}

Organisational culture is still a relatively new concept, and is the construct of organisational psychology, which aims to explain the notion of organisational behaviour. As is the case with any social, and in particular psychological phenomenon, there is no final and comprehensive definition.

Some definitions of organisational culture are as follows: "Organisational culture is a social glue that joins the members of an organisation through acceptance of mutual values, symbols and social ideals" (Smirichic, 1983). When it comes to organisations, culture is viewed as the general pattern of behaviour, shared beliefs and values that members have in common.

Conclusions on organisational culture can be drawn based on what people say, do and think within an organisation. It involves learning and transfer of knowledge, beliefs and patterns of behaviour within a specifc time frame. That means that organisational culture is quite stable and does not change so often. It usually determines the so-called tone of the company and patterns of human behaviour (Weihrich, Koontz, 1994.)

Organisational culture influences all facets of an organisation, including job satisfaction. Schmeider (1983) describes organisational culture as "the system of values and assumptions that determine the way in which business activities are performed in an organisation". However, when Schmeider (1975) talks about job satisfaction, he defines it as "personal evaluation of the present work conditions"... He further explains that job satisfaction is connected with individual perception and evaluation of one's own job. This clearly indicates strong correlation between organizational culture and job satisfaction, i.e., the way in which organizational culture is implemented affects employee reactions.

One of the most widely explored issues within the domain of organisational culture and organisational behaviour is job satisfaction. Generally speaking, it can be said that it is a multidimensional phenomenon affected by internal and external factors. This phenomenon is extremely complex and is not formed separately, but it depends on numerous variables, including organisational structure, working conditions and leadership, as an integral part of the concept of organisational climate and culture.

The most frequently used definition of job satisfaction is proposed by Locke (1976). He defines it as a satisfactory or positive emotional state, resulting from the appraisal of one's job or job experiences. Hulin i Judge (2003) also state that job satisfaction includes multidimensional psychological reactions to one's job, and that such reactions have cognitive, affective and behavioural components, which is in agreement with the statement that job satisfaction is measured through examining employees' attitudes (Judge, Klinger, 2008)

Locke (1976) explains that the understanding of the job related attitudes, i.e. understanding of job dimensions that are rather complex and interrelated in nature, is of vital importance for researchers. He lists the following job dimensions as the most common ones: type of job, salary, opportunities for progress, employee recognition, benefits, supervisors, colleagues, company and its management. Kerego i Mthupha (1997) perceive working conditions and job dimensions through observing the current recruitment policy, communication channels, employee participation in the decision-making process, security and good management.

The combination of factors that should definitely be taken into consideration regarding the impact on satisfaction, would include the following: anatomy and independence, benefits, career development opportunities, career advancement opportunities, compensation/ salary, communication between employees and management, job contribution to organisational goals, feeling safe in an organisation, flexibility in achieving balance between business and private life, job security, specific job training, management recognition of employee contributions, purpose of job, networking, opportunities to use one's own skills and potentials, organisation's attitude towards employee professional development, entire 
corporate culture, relationship with colleagues, relationship with the supervisor, the job itself, job complexity (Robbins and Judge, 2013).

The need to achieve high levels of employee satisfaction is based on the statement that motivated employees are satisfied employees. As part of organisational behavior, motivation is of vital importance for achieving the primary goals of an organization. Having that in mind, it is evident that it definitely pays off to invest in development of motivation programs and strategies. Motivated employees are willing to make additional effort and record better performance, which further contributes to enhancing the overall productivity and growth of an organisation.

\section{EMPLOYEE ENGAGEMENT}

Employee engagement can greatly contribute to the overall growth and smooth functioning of an organization. Managers should devote particular attention to finding, attracting and hiring individuals who possess not only necessary technical knowledge, but also other relevant social traits, such as devotion, loyalty, sociallyresponsible behavior etc., which all have a positive bearing on achieving wider interests.

All these segments are of vital importance when considering employee engagement, i.e. organizational behavior in one of its parts. However, despite the fact that individuals should possess these traits, that does not necessarily mean that they will positively affect an organization. It is crucial to determine the ways to stimulate and maintain these values for the sake of achieving successful business performance.

Kevin Kruse (2014) talks about employee engagement as an emotional attachment, and believes that when motivated, employees are more productive, give better service and even stay in their jobs longer. All that leads to more satisfied clients, who spend more money, and thus increase sales and profit.

In accordance with the research that provides an insight into specific positive outcomes of growing engagement, this field has attracted considerable interest in recent years. Four general reasons have been highlighted: 1) People have become the primary source of competitive advantage. The Brookings Institute has shown that in $1982,66 \%$ of an organization market value came from tangible assets (machine, goods, plant). In 2002, $80 \%$ of value came from intangible assets (brand, intellectual property, and the most important, the quality of workforce). 2) Despite large financial costs, considerable attention is devoted to employee engagement. Retaining key quality human resources and attracting talents is considered an imperative policy. 3) It has become evident that employee engagement is connected to motivation, and thus it is necessary to identify things that individuals do well and work on them, as well as to recognise and reward their achievements and effort. 4) The positive correlation between employee engagement and organisation's performance suggests that there is a substantial upside to organizations that focus on enhancing employee engagement, i.e. greater engagement leads to more favourable business performances (Wellins, Bernthal, Phelps, 2003).

Research has identified two key elements that are needed to truly boost employee engagement. The first one is the rational aspect, which is related to understanding of the business role, its position in an organization and the ways to harmonize the goals of certain job position with the overall organizational goals. The other aspect is emotional, and is concerned with how people feel about the organization, and whether their job provides them with the feeling of personal contribution, and how they are related to management (Armstrong, 2006).

We can analyse these two aspects through numerous factors affecting behavior, in particular through examining employee attitudes towards the issues related to their business roles and general feelings about the job. Organisations can use different methods to increase employee engagement. The three most relevant factors when choosing the appropriate method are employees, leaders, and organizational system and strategies (Wellins, Bernthal, Phelps, 2003).

Pursuant to the above-stated, it was necessary to develop an instrument that would be adequate enough to measure engagement, paying attention to what it represents and what components may affect it. To that end, an employee engagement survey was developed as a method that can enable communication with employees, based on which it could be possible to measure the level of engagement. It is a method that has been observed and confirmed as purposeful by numerous studies.

Engagement survey, i.e. measurement of the main engagement drivers within an organization based on which it is possible to determine the level of engagement, was the main reason for choosing this method. It is based on the assumption that satisfied employees are those who are motivated, and that they will invest more efforts into doing successfully their job assignments. 
As regards drivers, there are no official standards, but the most common ones are: opportunities for progress, recognition, salary and benefits, role in an organization, training and development, job opportunities, leadership and its impact, work environment etc.

This method also aims to encourage communication with employees, as it provides us with necessary feedback. Practice that company uses to measure the components such as employee satisfaction and leadership and management efficiency and impact of work environment, provides the company with necessary information on what should be changed. Also, using a questionnaire to get necessary information enables communication with similar organisations or research endeavours in the field.

\section{RESEARCH RESULTS AND DISCUSSION}

The subject of our research is the company for software design and development, which has shown to be very successful both at regional and European level. Research was conducted based on an anonymous survey. Besides questions related to determining the structure of cause (gender, age, work experience in the company, sector $e t c$.), the survey contains 42 statements grouped into categories. The survey for the herein observed company was designed in a way that would give a clear picture of the following categories: overall feelings about the workplace or overall satisfaction; relationship and feelings for the first line supervisor or team leader; feelings for the team in which one works; feelings for one's personal performance and evaluation; attitude towards leaders, planning and communication; training and development; salary and benefits.

Out of 160 employees in the company, 157 have completed an anonymous survey, which provides a very high response rate for engagement survey. All survey statements are grouped into 9 categories that represent critical job facets. The average value of responses was calculated for each category (i.e. the sum of arithmetic means).

I. The research results for the observed categories are as follows: I. My first-line supervisor (4.47): My first-line supervisor treats me well and respects me (4.82); My-first line supervisor recognizes and awards my positive performance (4.60); I consider my first-line supervisor a competent professional (4.83). My first-line supervisor values my opinion, talent and contribution (4.62);
My first-line supervisor sets realistic and clear expectations regarding my performance (4.42); My first-line supervisor regularly provides me with useful and constructive information (3.94). My first-line supervisor actively participates in my professional development (3.87).

II. Employees' overall feelings about the workplace (4.47): I would recommend a friend to look for the job in the company (4.63); I consider my work environment satisfying and motivating (4.55); I am proud to be part of the company (4.53); I plan to develop my own career within the company in the following two years or more (4.31); Most of the time I feel happy to be part of the company (4.32).

III. My role in the company (4.31): I am completely aware of my role in the company (4.50), I have the authority to decide on the things related to my job (4.33); My job enables me to adequately explore my skills and abilities (4.13); I am motivated to do more than formal work activities $(4,25)$; The level of stress I am exposed to is acceptable considering my role and volume of responsibilities (4.21); I dispose of adequate resources necessary to do my job well (4.41).

IV. My team (4.40): The cooperation and communication between colleagues in my team is extremely good (4.67); My team leader actively participates in giving instructions and monitoring my work and strengthening of my motivation for the current job (4.14).

V. Leadership, planning and communication (4.19): I understand the vision and business strategy of the organisation (4.48); I feel that I can express my opinion honestly and give suggestions concerning necessary changes without being afraid of possible consequences (4.32); Leaders in the company act for the wellbeing of all employees (4.57); I am familiar with the things that happen in the organisation (4.06); Organisation gives me enough recognition for the things I do well (4.04); I am conversant with the feedback provided by clients and their satisfaction (4.20); Goals are adequately set within my team (4.02); I need to be consulted in advance about the changes that can affect me (3.79); There is good cooperation and communication between the teams in the organisation (4.02).

VI. Performance and evaluation (4.26): I understand the process of performance evaluation and its rel- 
evance (4.56); the analysis of my performance is done on a regular basis (4.05); I believe that my performance is objectively assessed (4.18).

VII. Training and development (3.98): I am encouraged to explore the opportunities for growth and improvement in the organisation (4.37); I am familiar with the skils and experience cruicial for my career development (4.31); Organisation provides me with sufficient training (3.26).

VIII. Orientation and 'entry' into the organisation (3.86): My role in the organistion was adequately presented to me during recruitment process (3.95); I was provided with enough training upon entering the organisation, which has enabled me to do my job efficiently (3.77).

IX. Compensation and benefits (3.57): Generally speaking, I am satisfied with the benefits package (3.84); I am well-paid for the job I do (3.74); My salary is competitive in relation to the market (3.14).

The possible responses are provided in the following form: I fully disagree; I disagree; I neither agree nor disagree; I agree; I fully agree.

The statistical analysis included comparison of mean values $(\mathrm{Mx})$ of each category in relation to: the time when the survey was conducted (2014 and 2015 respectively) and the length of employment of the surveyed participants. The value of each category $(\mathrm{Mx})$ was compared with the sum of mean values of all the categories (4.14). Two-sample T-test was carried out, using a PHStat2 program, to devise the $\mathrm{p}$-value for the set of means regarding the time of survey and the length of employment (Table 1) and cross-category comparison (Table 2).

Any variable having significance at some arbitrary levels can be selected for data analysis. More traditional levels of significance, such as 0.05 , can fail to identify variables known to be important for this type of business researh. According to the Laerd Statistics (2015), we may need to increase the value of significance making the study less robust in terms of error, and easier to recognize statistically significant differences. To that end, we decided to use significance level of 0.2 since this introductory study should show all the variables important for building the analysis model. Hence, ${ }^{*}$ asigned to certain mean values in the Tables 1 and 2 represents the computed p-value $\leq 0.2$.

\begin{tabular}{|c|c|c|c|c|}
\hline & \multicolumn{2}{|c|}{$\begin{array}{l}\text { Time of the } \\
\text { survey }\end{array}$} & \multicolumn{2}{|c|}{$\begin{array}{l}\text { Length of em- } \\
\text { ployment }\end{array}$} \\
\hline & 2014 & 2015 & $\begin{array}{l}>2 \\
\text { years }\end{array}$ & $\begin{array}{c}<1 \\
\text { year }\end{array}$ \\
\hline I. Overall feelings & 4.15 & $4.47^{\star}$ & 4.44 & $4.58^{\star}$ \\
\hline $\begin{array}{l}\text { II. My first-line } \\
\text { supervisor }\end{array}$ & 4.20 & $4.47^{\star}$ & 4.27 & $4.59^{*}$ \\
\hline III. My team & 4.16 & $4.31^{\star}$ & 4.25 & $4.39^{*}$ \\
\hline $\begin{array}{l}\text { IV. My role in the } \\
\text { company }\end{array}$ & I & 4.41 & 4.38 & 4.52 \\
\hline $\begin{array}{l}\text { V. Performance } \\
\text { and evaluation }\end{array}$ & 3.87 & $4.19^{*}$ & 4.03 & 4.35 \\
\hline $\begin{array}{l}\text { VI. Leadership } \\
\text { planning, com- } \\
\text { munication }\end{array}$ & I & 4.26 & 4.33 & 4.29 \\
\hline $\begin{array}{l}\text { VII. Training and } \\
\text { development }\end{array}$ & 3.64 & 3.98 & 3.94 & 4.05 \\
\hline $\begin{array}{l}\text { VIII. Orientation } \\
\text { and entry into } \\
\text { the company }\end{array}$ & / & 3.86 & 3.54 & $3.96^{*}$ \\
\hline $\begin{array}{l}\text { IX. Compensation } \\
\text { and benefits }\end{array}$ & 3.28 & 3.57 & 3.22 & $3.78^{\star}$ \\
\hline
\end{tabular}

Table 1. Comparison of Means ( $\mathrm{Mx})$ by categories

\begin{tabular}{ccccccccccc}
\hline & & & & & & & & & & \\
& & II & III & IV & V & VI & VII & VIII & IX \\
\hline Mx & $4.47^{*}$ & $4.47^{*}$ & $4.31^{*}$ & 4.41 & 4.19 & 4.26 & 3.98 & $3.86^{*}$ & $3.57^{*}$
\end{tabular}

Table 2. Comparison of means $(\mathrm{Mx})$ between categories

Based on the above-given results, statistically significant improvement of employee engagement could be observed in 2015 for the categories I, II, III and V compared to the previously surveyed period (Table 1). This is an indicator of improvement of organizational culture within the company for these categories, i.e., a measure of positive impact influenced by organizational culture activities that were carried out within the company during the above-mentioned time period.

Furtehrmore, there is a statistically significant difference of engagement in regard to the length of employment in an organization. Employees with the shortest length of employment (up to one year) showed higher engagement mean values in relation to the employees with longer length of employment (more than 2 years) (Table 1). 
This phenomenon, which is common in practice, was supported by research showing that most employees are strongly motivated at the beginning of their employment, but motivation tends to decline over time. This research was conducted in 100 companies and included over 1.2 million employees, and its findings could be considered relevant in $85 \%$ of companies ((Sirota, Mischkind, Meltzer, 2006).

The overall results in Table 1 lead us to the conclusion that the categories I, II and III are enablers of organizational culture, while VII and IX represent barriers and obvious areas for improvement. We recommend that the corrective plan of actions for improving organizational culture should be based on mutual comparison of categories and their dimensions (i.e. proposed questions) that determine them as a true measure of employee engagement for various job facets of engagement survey. This approach permits a more complete picture of employee engagement and clearly distinguishes between different levels of satisfation with various job facets (Spector, 2008).

Individual questions in each category cannot be compared by means of a statistical analysis due to variability of the sample size, as certain categories are determined by two to three, while others with nine to ten questions.

Statistical analysis has shown that categories VIII and IX are the areas that require most change, and the authors shall briefly present the corrective actions stemming from the present research.

Within the category VIII (Orientation and entry into company), both statements demonstrate low rates: I was provided with enough training upon entering the organisation, which enabled me to successfully do my job (3.77) and I was made conversant with my role in the organisation during the recruitment process (3.95). We suggest the following corrective actions: 1) Run a training needs analysis (TNA) to determine training/development requirements per employee, team and organization; 2) Set up an employee orientation program for all newcomers and junior employees; 3 ) Improve the current mentorship system, by asigning personal responsibilties to future mentors and mentorship standards they have to meet; 4) Install regular two-way feedback with the newcomers to get an insight into their attitudes, relationship with the mentor and current progress.

Compensation and benefits was the lowest rated category (IX) for the following statements (questions): My salary is competitive in relation to the market (3.14); I am well paid for what I do $(3,74)$, and I am satisfied with the benefits package (3.84). We suggest the following corrective actions: 1) Run a compensation and benefits survey within competitive industries in Serbia to determine market wage for each position; 2) Devise a communication plan and carry out series of meetings with employees to discuss the current compensation and benefits model; 3) Organize a series of focus groups with employees to gain bottom-up information of their engagement as a stepping stone for devising the organizational corrective action plan to deal with all the issues such as: work-life balance, overtime working hours, organizational structure, performance management, compensation and benefits model, feedback, etc.

Furthermore, within the categories that were generally positively rated, communication appears as a potential denominator, i.e., the source of the problem. Besides the activities proposed, it is necessary to devote special attention to communication as the key factor for the improvement of functions of an organization. Accordingly, special attention should be assigned to leadership communication skills.

\section{CONCLUSION}

The results of the engagement survey indicate the necessity of fully mobilising organizational resources to improve the organizational culture. Improvements made within categories I, II, III and V over the past 12 months render certain actions plausible and open the possibility to check other categories. This is particularly appropriate for the categories VIII and IX that require special attention in dealing with certain issues. Therefore, structured corrective action plans have been proposed.

However, the lack of systematic approach in dealing with certain issues shall mobilise management of an organization to devise and implement tailor-made solutions. Faceted approach based on mutual comparison of categories and their building blocks (dimensions) enables a detailed overview of job satisfaction. This in turn provides a clear picture of the areas for improvement, as well as the key enablers of organizational culture.

Subesquently, this paper provides a guide that can be implemented within any organization with the aim to address the issue of employee engagement and compare organizational culture and climate. The statements expressing job process and employee attitudes clearly indicate possible steps and measures that could improve the overall business performances of an organisation and lead to more favourable business outcomes. 


\section{REFERENCES}

Armstrong, M. (2006). Handbook of Human Resource Management practice, London and Philadelphia: Cogan page.

Judge, T., \& Klinger, R.,(2008), Job Satisfaction,Subjective Well-Being at Work. In Eid M., Larsen R., The Science of Subjective Well-Being (393-413). New York, The Guilford Press

Kerego, K., \& Mthupha, D.M. (1997), Job satisfaction as perceived by agricultural extension workers in Swaziland South African Journal of Agricultural Extension, pp. 19-24

Kevin, K. (2012). Why Employee Engagement? Forbes Leard Statistics (2015). Hypothesis Testing, https:// statistics.laerd.com/statistical-guides/hypothesistesting-3.php

Locke, E.A. (1976). The nature and causes of job satisfaction. In M.D. Dunnette (Ed.), Handbook of industrial and organizational psychology pp. 1297-1349. Chicago: Rand McNall

Petković, M., Janićijević, N., \& Milikić, B. (2010). Organizacija, Beograd: Centar za ozdavačku delatnost Ekonomskog fakulteta

Robbins, S., \& Judge, T. (2013). Organizational Behavior, New York, Library Of Congress Cataloging-inPublication Data

Schneider, B., \& Reicher, A.E. (1983). On the etology of climates, Personnel Psychology, Vol. 36: 19-37.
Schneider, B, \& Synder, R.A. (1975), Some relationship between job satisfaction and organizational climate, Journal of Applied Psychology, 60(3):318-328

Semphane, M, Rieger, H., Roodt, G., (2012) Job Satisfaction in Relation to Organisational Culture. SA Journal of Industrial Psyhology, Vol 28, No 2, pp. 23-30

Sirota, D., Mischind, L., Meltzer, M. (2006), Why Your Employees are Losing Motivation, Harvard Mangement Update, Vol. 11

Smirichic, L. (1983). Concepts of Culture and Organizational Analysis. Administrative Science Quarterly, 28(3), 339-358

Spector, P. (2008). Feelings About Work: Job Attitudes and Emotions, in: Industrial and Organizational Psychology, John Wiley \& Sons, Hoboken, str. 222251.

The Impact of Employee Engagement on Performance. (2014). Harvard Business Review, Harvard Business review analytic services, Sponsored by Achivers

Torrington, D., Hall, L., \& Taylor, S. (2004) Menadžment ljudskih resursa, Beograd: Data status

Weihrich, H., \& Koontz, H. (1994). Menadžment. Zagreb: Mate.

Wellins, R., Bernthal, P., \& Phelps, M. (2003). Employee Engagement: the key to realizing competitive advantage. San Francisco: Development Dimension International 